\title{
Nomogram of Follicle Stimulating Hormone Starting Dose Based on Antral Follicle Count, Third Day Follicle Stimulating Hormone Levels, and Age in Hasan Sadikin Hospital Bandung
}

\author{
Tono Djuwantono, Dian Tjahyadi, Mohammad Wahyu Ferdian \\ Department of Obstetrics and Gynecology, Hasan Sadikin Hospital, Faculty of Medicine, Universitas \\ Padjadjaran, Bandung, Indonesia \\ Email: djuwantono@yahoo.com
}

Received 22 February 2016; accepted 23 May 2016; published 26 May 2016

Copyright (C) 2016 by authors and Scientific Research Publishing Inc.

This work is licensed under the Creative Commons Attribution International License (CC BY). http://creativecommons.org/licenses/by/4.0/

(c) (i) Open Access

\begin{abstract}
The main aspect of in vitro fertilization (IVF) cycle individualization is to offer every patient the best therapy adjusted to each individual characteristic. Usually, clinicians choose the FSH starting dose based on anamnesis and clinical criteria, the most important is the results of previous IVF. If there are no previous cycles, the criteria will be based on the patient's age, body mass index (BMI), and markers of ovarian reserve. The issue is whether an follicle stimulating hormone (FSH) starting dose nomogram based on antral follicle count (AFC) amount, third day FSH serum levels, and age are suitable to female patients who are going through IVF in Aster Clinic Hasan Sadikin Hospital Bandung. This study aims to create a nomogram based on AFC and age to calculate the correct FSH starting dose for IVF therapy in Aster Clinic Hasan Sadikin Hospital Bandung. The research type in this study is observational analytic with a retrospective cohort design, which is a type of research that study outcomes which are evaluated at certain time points. This type of research seeks to study the dynamic of relationships or correlations between risk factors with its impact or effects. Risk factors and impacts or effects are observed simultaneously, which means that the research subject is observed once and risk factors including effects are measured based on the situation or status at the time of observation. The result of this study is a nomogram designed based on AFC and age to calculate the correct FSH starting dose for IVF therapy. The nomogram will be used in Aster Clinic Hasan Sadikin Hospital Bandung.
\end{abstract}




\section{Keywords}

\section{AFC, Age, BMI, FSH, IVF, Nomogram}

\section{Introduction}

The main aspect of IVF cycle individualization is to offer every patient the best therapy adjusted to each individual characteristic. Therefore, allowing the possibility of a high success rate, and also minimalizing risks that originate from ovarian stimulation. Choosing a different gonadotropin dosage for each patient is a significant clinical decision in personalizing therapy. Although exogenous FSH has been used for decades, and millions of cycles have been performed all over the world, the criteria to choose the correct initial dose of FSH have not yet been identified. Usually, clinicians choose the FSH starting dose based on anamnesis and clinical criteria. The most important is the results of previous IVF. If there are no previous cycles, the criteria will be based on the patient's age, BMI, and markers of ovarian reserve [1] [2].

One of the markers currently used to determine ovarian reserve is AFC, which has one of the best performances in predicting ovarian response towards exogenous FSH [3]-[5]. Ovarian antral follicle with a size larger than 2 $\mathrm{mm}$ is very sensitive and responsive towards FSH and is defined as recruitable. They can be seen and measured with transvaginal ultrasonography (USG). AFC is the amount of follicles sized 2 - $10 \mathrm{~mm}$ from both ovarium [6] [7]. Therefore, AFC can predict with high accuracy how well the follicle pool responds to exogenous FSH.

There are published studies reporting the excellent correlation between AFC and ovarian response in the IVF program [8] [9]. AFC can also correlate with the event of menopause transition that indicates a close relationship with the quantitative aspects of ovarian reserve [10]. The advantage of AFC is the possibility that the measurement is performed concurrently while the clinician examines the patient, therefore there is possibility that AFC will always be the marker widely used to determine ovarium reserve.

Recently, a study published a nomogram to calculate the FSH starting dose in the IVF cycle [11]-[13]. The nomogram is based on patient's age, third day FSH levels, and anti-mullerian hormone (AMH), and also can be a reference for individualized dosage for all patients in the healthcare setting that uses AMH to determine ovarium reserve. Meanwhile, the important role of AFC in identifying extreme ovarian response has been proved [8] [9]. Its role in therapy individualization such as FSH starting dose needs to be further explained. Therefore, we intend to investigate whether it is possible to create a nomogram based on AFC, so clinicians can decide on the correct initial exogenous gonodatropin dose in the IVF cycle, whose purpose is to reduce the possibility of extreme ovarian response.

The issue is whether an FSH starting dose nomogram based on AFC amount, third day FSH serum levels, and age are suitable to female patients who are going through IVF in Aster Clinic Hasan Sadikin Hospital Bandung. The purpose of this research is to create a nomogram based on AFC and age to calculate the correct FSH starting dose for IVF therapy in Aster Clinic Hasan Sadikin Hospital Bandung.

\section{Methods}

The study design was retrospective cohort. The study was held in March to May 2015 at Aster Clinic Hasan Sadikin Hospital Bandung. The study was done on patients going through IVF therapy at Aster Clinic Hasan Sadiking Hospital Bandung. In this study the sample size was selected for the study purpose was 60 people. This research has been approved by ethics committee in Faculty of Medicine, Universitas Padjadjaran.

The research type in this study was observational analytic with a retrospective cohort design, which is a type of research that study outcomes which are evaluated at certain time points. This type of research seeks to study the dynamic of relationships or correlations between risk factors with its impact or effects. Risk factors and impacts or effects was observed simultaneously, which means that the research subject was observed once and risk factors including effects was measured based on the situation or status at the time of observation. Stages of this research can be seen in Figure 1.

\section{Data Analysis}

The obtained data were recorded in the research form which was previously created, then was edited, verified, 


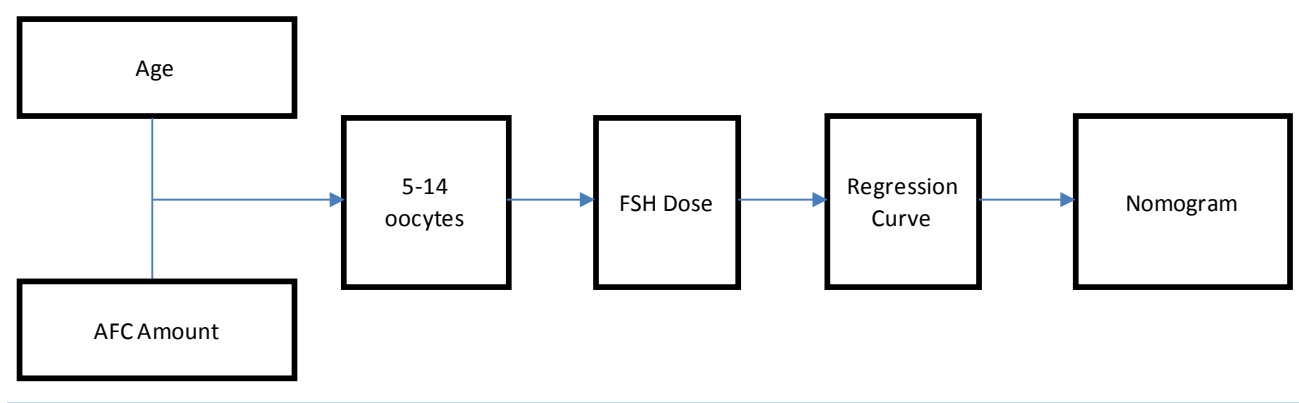

Figure 1. Steps in research.

coding and data entry, and afterwards the data were analyzed. Analysis was performed to obtain the prevalence value, which was retrospectively analyzed data from 60 medical records that contain clinical information and AFC of patients that successfully participated in the IVF program and data demographics of research subjects at the Aster Clinic dr. Hasan Sadikin General Hospital.

Appropriate statistical analysis of research objectives and hypotheses is used to determine the correlation between them. Statistical analysis for categorical data was tested by Chi-Square test and Fisher test and Kolmogorov-Smirnov test as the alternative if the requirement of the Chi-Square is not met. Meanwhile, to test the hypothesis of statistical correlation between the two numeric variables is using Pearson correlation test if the data were normally distributed and Spearman correlation test as the alternate if the data are not normally distributed. To analyze the magnitude of correlation is using criteria Guilford. Interpretation the results of hypothesis testing based on the strength of the correlation, the direction of correlation, and p-value: The strength of correlation (r) based on criteria Guillford (1956), The data obtained are recorded in a special form and then processed through SPSS version 21.0 for Windows.

In this discussion which is simple linear regression analysis, the linear relationship observed is a linear relationship between the independent variables with one variable dependent.

\section{Results and Discussion}

The purpose of the study is to determine the dose of FSH by the value of AFS and age of patients, carried out using multiple linear regression analysis. Before performed a multiple regression analysis, there are some sort of test:

\subsection{Classical Assumption Test}

\subsubsection{Normality Test}

One of the assumptions that must be fulfilled in the establishment of best regression model (BLUE) is a normal distribution of the residual is $\varepsilon \sim \mathrm{N}\left(0, \sigma_{\varepsilon}^{2}\right)$, which means that the data analyzed samples taken from normally distributed population. In this study, the normality test was done descriptively by looking at the graph plots between the value of the dependent variable and its residual. Normality in the regression model can be seen from Normal P-P Plot of output SPSS 21.0 as seen in Figure 2.

Figure 1 shows clearly that the data points tend to follow a straight line so that it can be concluded that the error $(\varepsilon)$ is in normal distribution. This indicates that the regression model to meet the standard distribution of normality so that the normality assumption is fulfilled.

\subsubsection{Test Multicollinearity}

After normality test, further multikolenieritas assumptions test needs to be done. A good regression model is a regression model that is free of the multicollinearity between independent variables. Multicolinierity test is done by looking at the tolerance value and Variance Inflation Factor (VIF). Multicollinearity happened if VIF above of 10 or the tolerance value below 0.10 . If the VIF for the independent variable is greater than 10 , then one variable that correlated among variables should be reduced from the regression model. Multicollinearity is a very high correlation or very low correlation that occurred between the relationship of the independent variables. Multicollinearity test in this study is done by using Variance Inflation Factor (VIF) and output obtained by SPSS 21.0 as follows: 


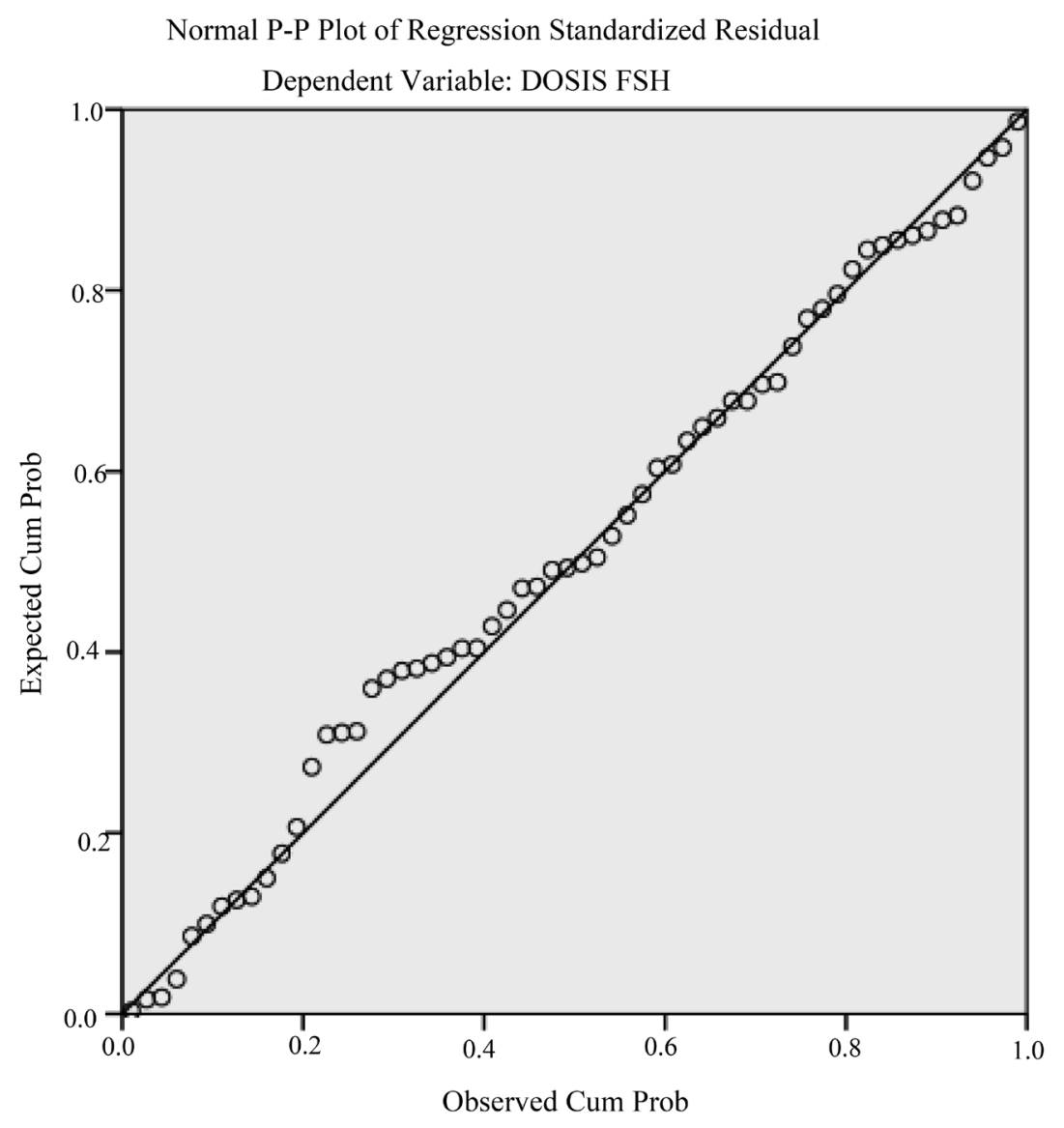

Figure 2. Normality test results.

From the multicollinearity test results in Table 1 , VIF is smaller than the 10 or tolerance above 0.1 . From the table was obtained that all VIF values below 10 or tolerance values above 0.1 , so that it can be concluded there are no multicollinearity between independent variables that exist. It can be concluded that there are no symptoms of multicollinearity between independent variables. Thus, the regression equation meet the assumptions of non-multicollinearity.

\subsubsection{Heteroscedasticity Test}

Heteroscedasticity indicates that the variance of variable is not the same for all observations. Heteroscedasticity test using scatterplot test. The purpose of heteroscedasticity test is to examine whether the regression model occurred inequality variance of the residuals of an observation to another observation. A good regression model means there is no heteroscedasticity. To detect the presence of heteroscedasticity is done by embodying a scatter plot between the estimated value with the residue. The heteroscedasticity test results are shown in Figure 3:

As seen in Figure 3, the points spread randomly between the zero axis of the bottom and top, and do not form a particular pattern. It can be concluded that there is no heteroscedasticity in research. So the asumption of heteroscedasticity is fullfilled.

\subsection{Correlation Analysis}

To determine the relationship between the variables in the study, the variables in this research are the value of AFS and age of patients with variable dose FSH. Calculations were performed using SPSS 21.0, with the following results:

The results from Table 2, to interpret the correlation used the following criteria:

1) 0 to 0.19 : correlation is very low. 
Table 1. Multicollinearity test results.

\begin{tabular}{rrrr}
\hline & & \multicolumn{2}{c}{ Collinearity Statistics } \\
\cline { 3 - 4 } Model & & Tolerance & VIF \\
\hline & (Constant) & & 1.274 \\
& PATIENT AGE & 0.785 & 1.274 \\
\hline
\end{tabular}

Tabel 2. Spearman correlation test results.

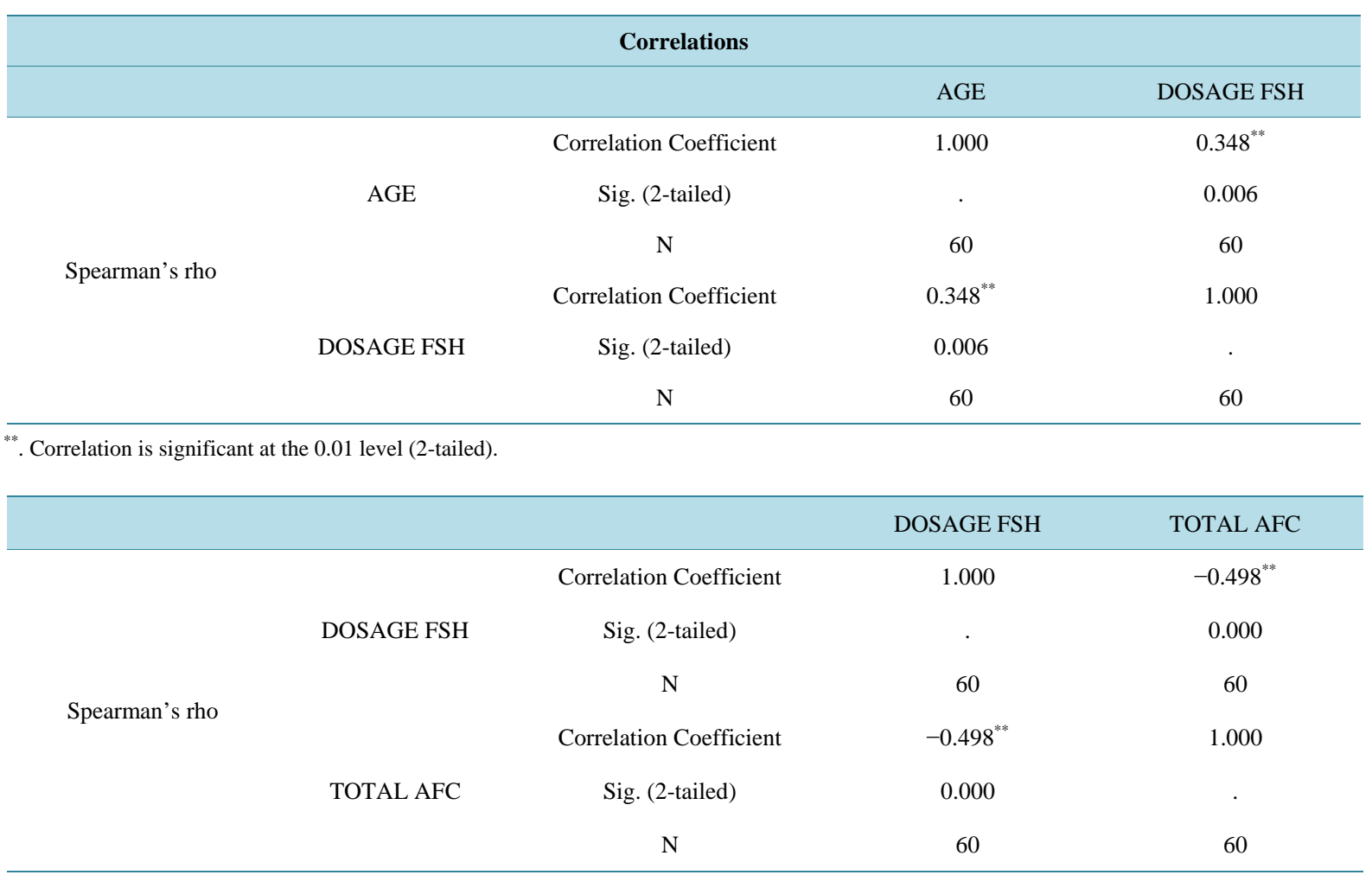

\footnotetext{
${ }^{* *}$. Correlation is significant at the 0.01 level (2-tailed).
}

2) $>0.20$ to 0.399 : low correlation.

3) $>0.40$ to 0.599 : correlation is strong enough.

4) $>0.60$ to 0.799 : strong correlation.

5) $>0.80$ to 1.000 : very strong correlation.

So we can conclude that the correlation between the dose of FSH and the age of the patient are included in the low category, while the correlation between the dose of FSH and AFC are included in the strong enough category.

\subsection{Determination Coefficient}

To see the magnitude of linear relationship between age of the patient and the dose of the AFC and FSH, it can be based on the calculation of SPSS 21.0 statistical software by looking at the numbers R Square as below.

From Table 3, it can be seen that the results of R Square is 0.281 which shows the influence of independent variable $(\mathrm{X})$ is the age of the patient and the AFS to FSH (Y). The amount of Coefficient Determination (CD) can be formulated as follows:

$\mathrm{KD}=\mathrm{R}$ Square $\times 100 \%$. 


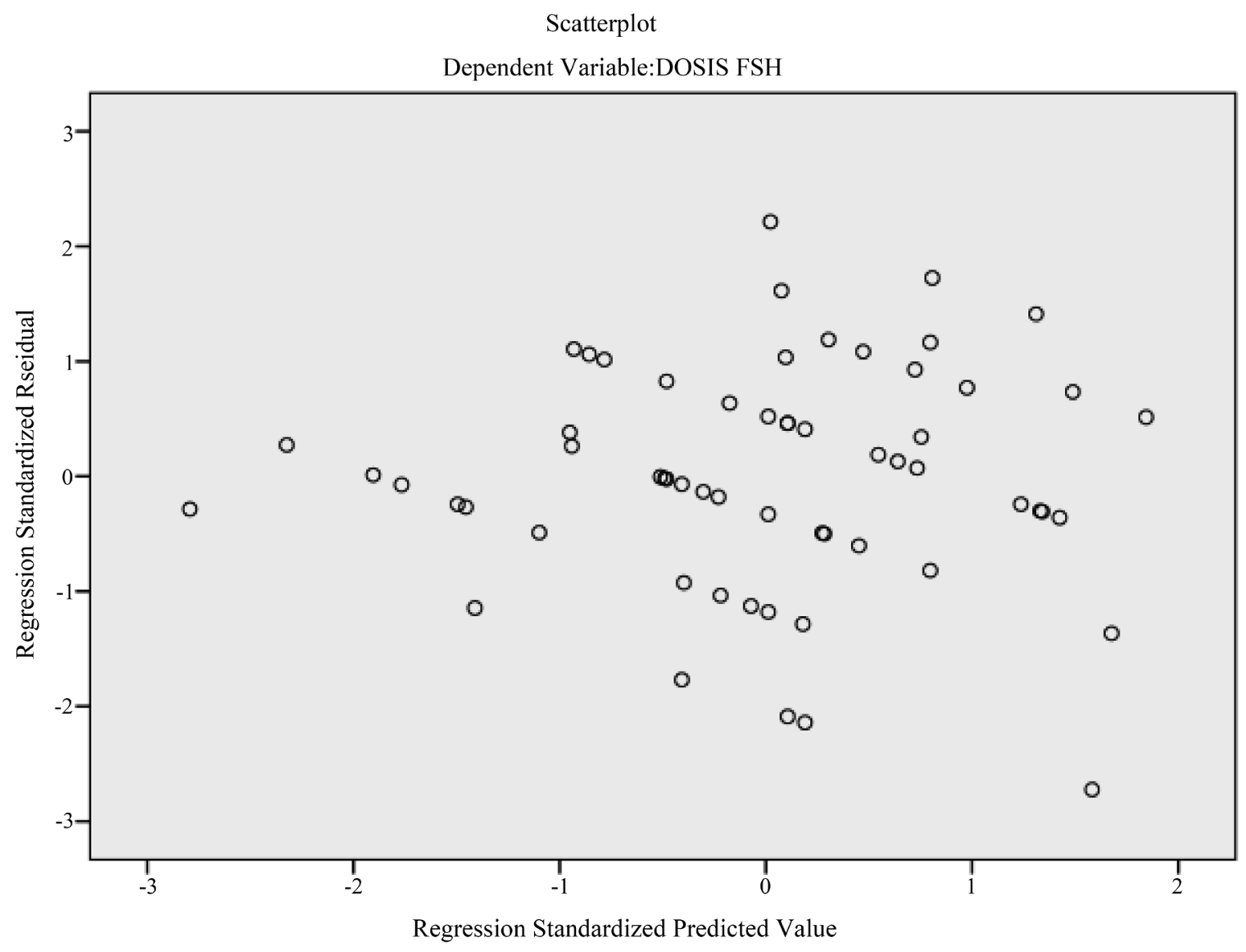

Figure 3. Heteroscedasticity test results.

Table 3. R test result.

\begin{tabular}{ccccc} 
& \multicolumn{4}{c}{ Model Summary $^{\mathbf{b}}$} \\
\hline Model & $\mathrm{R}$ & R Square & Adjusted R Square & Std. Error of the Estimate \\
\hline 1 & $0.530^{\mathrm{a}}$ & 0.281 & 0.256 & 88.57745 \\
\hline
\end{tabular}

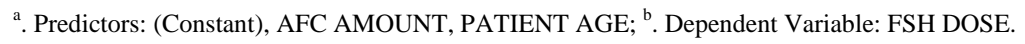

$$
\begin{aligned}
\mathrm{KD} & =0.281 \times 100 \% . \\
\mathrm{KD} & =28.1 \% .
\end{aligned}
$$

This figure shows the results of determination coefficient of independent variable (X) and explain it's influence or relationship to the dose of FSH (28.1\%). While the remaining $71.9 \%$ influenced by the other factors that are not examined.

\subsection{Hypothesis Test}

Hypothesis test in this study is divided into two, the simultaneous test using the $\mathrm{F}$ test and partial test using $\mathrm{T}$ test.

\section{a. Hypothesis Test Simultaneously}

Hypothesis test simulataneously by $\mathrm{F}$ test. If $\mathrm{p}$ value less that $0.05(\mathrm{p}<0.05)$ means it's statistically significant. The result of hypothesis test in this study are shown in Table 3 and Table 4.

From the result of hypothesis test simultaneously obtains the number of significance 0.000 . So $\mathrm{H}_{0}$ is rejected and $\mathrm{H}_{1}$ is approved. The number of result means that the alternative hypothesis $\mathrm{IH}_{1}$ is acceptable because $0.000<$ 0.05 and there is a linear relationship between age of patients and AFC to FSH. 
Table 4. Hypothesis test simultaneously (F Test).

\begin{tabular}{|c|c|c|c|c|c|c|}
\hline \multicolumn{7}{|c|}{ ANOVA $^{a}$} \\
\hline & Model & Sum of Squares & $\mathrm{df}$ & Mean Square & $\mathrm{F}$ & Sig. \\
\hline \multirow{3}{*}{1} & Regression & 174613.386 & 2 & 87306.693 & 11.128 & $0.000^{\mathrm{b}}$ \\
\hline & Residual & 447219.947 & 57 & 7845.964 & & \\
\hline & Total & 621833.333 & 59 & & & \\
\hline
\end{tabular}

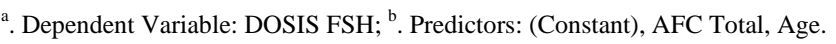

\subsection{Partial Hypothesis Testing}

We used $\mathrm{T}$ test as partial hypothesis testing and analyze its number of significance number. If $\mathrm{P}<0.05, \mathrm{H}_{0}$ is rejected and $\mathrm{H}_{1}$ is accepted. To measure the size of significance we used Beta of standardized coefficients. If it is $<0.05$, we can conclude that hypothesis is accepted. The result of hypothesis testing is showed in Table 5.

Out of 60 subjects with 5\% significant level, we concluded that not all variable has significant result.

\subsection{Multiple Linier Regression Analysis}

Multiple linier regression analysis is used to predict dependent variable based on its independent variable. In this study, independent variables (X) were patient's age and AFC level, which used to predict dosage of FSH. The formula of linear regression analysis used in this study:

$\mathrm{Y}=\mathrm{a}+\mathrm{b}_{1} \mathrm{X}_{1}+\mathrm{b}_{2} \mathrm{X}_{2}+\mathrm{e}$

Note:

$\mathrm{Y}$ : FSH dose.

$\mathrm{X}_{1}$ : Patient's age.

$\mathrm{X}_{2}$ : AFC level.

a: Constant.

$b_{1}, b_{2}$ : Regression coefficient.

e: error term.

Here is the result of multiple linear regression analysis from statistic software of SPSS 21.0:

Result of significance test in Table 6 showed $\mathrm{P}=0.000$. $\mathrm{p}$ value used in this study is $<0.05$, thus in this study $\mathrm{H}_{0}$ was rejected and $\mathrm{H}_{1}$ was accepted. From Table 6 we can conclude that patient's age and AFC level is significant simultaneously and they were significant to FSH dose. The linear regression result and spearman correlation analysis results are shown in Table 7 and Table 8 respectively.

From Table 7, the result of multiple linear regression model was included into the regression formula. Here is the formula in this study:

$\mathrm{Y}=162.342+4.809 \mathrm{X}_{1}-10.409 \mathrm{X}_{2}+\mathrm{e}$.

\subsection{Regression Analysis of Basal FSH and FSH Dose}

\subsubsection{Correlation Analysis}

We conducted correlation analysis to mesure significance of correlation between all variable in this study. Variables are AFS level and patient's age with FSH dose variable. Analysis was done using SPSS 21.0, as follows:

We used criteria below to interpret the result:

1) 0 - 0.19: very low correlation.

2) $>0.20$ - 0.399: low correlation.

3) $>0.40$ - 0.599: moderately strong correlation.

4) $>0.60-0.799$ : strong correlation.

5) $>0.80-1.000$ : very strong correlation.

Therefore we concluded that FSH dose and Basal FSH had low correlation. 
Table 5. Partial hypothesis analysis.

\begin{tabular}{|c|c|c|c|c|c|c|}
\hline \multicolumn{7}{|c|}{ Coefficients $^{\mathrm{a}}$} \\
\hline & \multirow{2}{*}{ Model } & \multicolumn{2}{|c|}{ Unstandardized Coefficients } & \multirow{2}{*}{$\begin{array}{c}\text { Standardized } \\
\text { Coefficients } \\
\text { Beta }\end{array}$} & \multirow[t]{2}{*}{$\mathrm{t}$} & \multirow{2}{*}{ Sig. } \\
\hline & & B & Std. Error & & & \\
\hline \multirow{3}{*}{1} & (Constant) & 162.342 & 128.005 & & 1.268 & 0.210 \\
\hline & PATIENT'S AGE & 4.809 & 3.368 & 0.175 & 1.428 & 0.159 \\
\hline & AFC LEVEL & -10.409 & 2.923 & -0.436 & -3.561 & 0.001 \\
\hline
\end{tabular}

a. Dependent Variable: FSH DOSE.

Table 6. Result of multiple linear regression analysis (ANOVA).

\begin{tabular}{|c|c|c|c|c|c|c|}
\hline \multicolumn{7}{|c|}{ ANOVA $^{a}$} \\
\hline & Model & Sum of Squares & df & Mean Square & $\mathrm{F}$ & Sig. \\
\hline \multirow{3}{*}{1} & Regression & 174613.386 & 2 & 87306.693 & 11.128 & $0.000^{\mathrm{b}}$ \\
\hline & Residual & 447219.947 & 57 & 7845.964 & & \\
\hline & Total & 621833.333 & 59 & & & \\
\hline
\end{tabular}

a . Dependent Variable: FSH DOSE; ' . Predictors: (Constant), AFC LEVEL, PATIENTS AGE.

Table 7. Result of multiple linear regression (coefficient).

\begin{tabular}{|c|c|c|c|c|c|c|}
\hline \multicolumn{7}{|c|}{ Coefficients $^{\mathrm{a}}$} \\
\hline & \multirow{2}{*}{ Model } & \multicolumn{2}{|c|}{ Unstandardized Coefficients } & \multirow{2}{*}{$\begin{array}{c}\begin{array}{c}\text { Standardized } \\
\text { Coefficients }\end{array} \\
\text { Beta }\end{array}$} & \multirow{2}{*}{$\mathrm{t}$} & \multirow{2}{*}{ Sig. } \\
\hline & & B & Std. Error & & & \\
\hline \multirow{3}{*}{1} & (Constant) & 162.342 & 128.005 & & 1.268 & 0.210 \\
\hline & PATIENT'S AGE & 4.809 & 3.368 & 0.175 & 1.428 & 0.159 \\
\hline & AFC LEVEL & -10.409 & 2.923 & -0.436 & -3.561 & 0.001 \\
\hline
\end{tabular}

a. Dependent Variable: FSH DOSE.

Table 8. Result of spearman's correlation testing.

\begin{tabular}{|c|c|c|c|c|}
\hline \multicolumn{5}{|c|}{ Correlations } \\
\hline & & & BASAL FSH & FSH DOSE \\
\hline \multirow{6}{*}{ Spearman's rho } & \multirow{3}{*}{ BASAL FSH } & Correlation Coefficient & 1.000 & $0.336^{* *}$ \\
\hline & & Sig. (2-tailed) & . & 0.009 \\
\hline & & $\mathrm{N}$ & 60 & 60 \\
\hline & \multirow{3}{*}{ FSH DOSE } & Correlation Coefficient & $0.336^{* *}$ & 1.000 \\
\hline & & Sig. (2-tailed) & 0.009 & . \\
\hline & & $\mathrm{N}$ & 60 & 60 \\
\hline
\end{tabular}

\footnotetext{
${ }^{* *}$. Correlation is significant at the 0.01 level (2-tailed).
}

\subsubsection{Coefficient of Determination}

To see the linier correlation between basal FSH and FSH dose, we used R square in SPSS 21.0, as follow:

From Table 9, we conclude that R Square $=0.281$. This showed significance of independent variable $\mathrm{X}$, basal 
Table 9. Result of R testing.

\begin{tabular}{ccccc}
\hline & \multicolumn{4}{c}{ Model Summary $^{\mathbf{b}}$} \\
\hline Model & $\mathrm{R}$ & R Square & Adjusted R Square & Std. Error of the Estimate \\
\hline 1 & $0.260^{\mathrm{a}}$ & 0.067 & 0.051 & 99.99319 \\
\hline
\end{tabular}

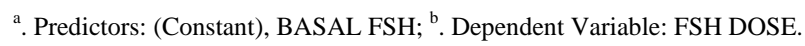

FSH, to FSH dose (Y). The value of coefficient of determination coefficient (CD) is formulated as:

$\mathrm{CD}=\mathrm{R}$ Square $\times 100 \%$.

$\mathrm{CD}=0.067 \times 100 \%$.

$\mathrm{CD}=6.7 \%$.

The result showed CD of independent variable (X) and explained its correlation or association with FSH dose as $6.7 \%$. While the rest, $93.3 \%$ is affected by other unidentified factors.

\subsection{Hypothesis Testing}

Hypothesis testing in this study was a partial testing using $\mathrm{T}$ test.

\subsubsection{Partial Hypothesis Testing}

Partial hypothesis testing using $\mathrm{T}$ test was conducted to analyse the number of significance. If $\mathrm{P}<0.05$, we reject $\mathrm{H} 0$ and accept $\mathrm{H}_{1}$. To measure the size of significance, we used Beta of Standardized Coefficient. If $\mathrm{P}$ is $<0.05$, we accept alternative hypothesis. The result of partial hypothesis testing in this study stated in this Table 10 .

Out of 60 patients, with 5\% level of significance, from partial hypothesis testing, we conclude that basal FSH has no significant correlation with FSH dose.

\subsubsection{Simple Linear Regression Analysis}

Simple linear regression analysis is used to to predict dependent variable based on its independent variable. In this study, dependent variable (X) was basal FSH, which used to predict FSH dose. The formula used in this study was:

$\mathrm{Y}=\mathrm{a}+\mathrm{b}_{1} \mathrm{X}_{1}+\mathrm{e}$.

Notes:

Y: FSH Dose.

$\mathrm{X}_{1}$ : Basal FSH.

a: Constant.

$\mathrm{b}_{1}$ : Coefficient Regression.

e: error term.

Below is the result of simple linear regregession analysis in SPSS 21.0 software:

Result of significance testing of Table 11 shows that $\mathrm{P}$ (Sig.) was 0.045 . Level of significance use in this study is 0.05 , thus we rejected $\mathrm{H} 0$ and accepted $\mathrm{H}_{1}$. Therefore from Table 11, we can conclude that Basal FSH was statistically significant to FSH dose. The regression formula is shown in Table 12.

From Table 12 in a simple linear regression model, we input the number into a regression formula. Here is the formula in this study:

$\mathrm{Y}=190.954+7.754 \mathrm{X}+\mathrm{e}$.

From the results of a statistical analysis of multiple parameters, we made a nomogram based on age and level of AFC (Figure 4) and based on the levels of FSH (Figure 5). In Figure 4, we can predict the starting dose of FSH based on age and AFC more easily. While in Figure 5, we can predict not only starting dose, but also basal FSH level.

\section{Conclusion}

Conclusions of this study are some variables such as age and the AFC can be used as a basis for making nomo- 
Table 10. Partial hypothesis testing.

\begin{tabular}{|c|c|c|c|c|c|c|}
\hline \multicolumn{7}{|c|}{ Coefficients $^{\mathrm{a}}$} \\
\hline & \multirow[t]{2}{*}{ Model } & \multicolumn{2}{|c|}{ Unstandardized Coefficients } & \multirow{2}{*}{$\begin{array}{c}\text { Standardized } \\
\text { Coefficients } \\
\text { Beta }\end{array}$} & \multirow[t]{2}{*}{$\mathrm{t}$} & \multirow[t]{2}{*}{ Sig. } \\
\hline & & $\mathrm{B}$ & Std. Error & & & \\
\hline \multirow{2}{*}{1} & (Constant) & 190.954 & 33.090 & & 5.771 & 0.000 \\
\hline & BASAL FSH & 7.754 & 3.787 & 0.260 & 2.047 & 0.045 \\
\hline
\end{tabular}

a. Dependent Variable: FSH DOSE.

Table 11. Result of simple linear regression analysis.

\begin{tabular}{|c|c|c|c|c|c|c|}
\hline \multicolumn{7}{|c|}{ ANOVA $^{a}$} \\
\hline & Model & Sum of Squares & df & Mean Square & $\mathrm{F}$ & Sig. \\
\hline \multirow{3}{*}{1} & Regression & 41912.297 & 1 & 41912.297 & 4.192 & $0.045^{\mathrm{b}}$ \\
\hline & Residual & 579921.036 & 58 & 9998.639 & & \\
\hline & Total & 621833.333 & 59 & & & \\
\hline
\end{tabular}

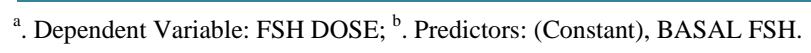

Table 12. Result of simple linear regression analysis (coefficient).

\begin{tabular}{|c|c|c|c|c|c|c|}
\hline \multicolumn{7}{|c|}{ Coefficients $^{\mathrm{a}}$} \\
\hline & \multirow{2}{*}{ Model } & \multicolumn{2}{|c|}{ Unstandardized Coefficients } & \multirow{2}{*}{$\begin{array}{c}\text { Standardized } \\
\text { Coefficients } \\
\text { Beta }\end{array}$} & \multirow[t]{2}{*}{$\mathrm{t}$} & \multirow{2}{*}{ Sig. } \\
\hline & & B & Std. Error & & & \\
\hline \multirow{2}{*}{1} & (Constant) & 190.954 & 33.090 & & 5.771 & 0.000 \\
\hline & BASAL FSH & 7.754 & 3.787 & 0.260 & 2.047 & 0.045 \\
\hline
\end{tabular}

a. Dependent Variable: FSH DOSE.

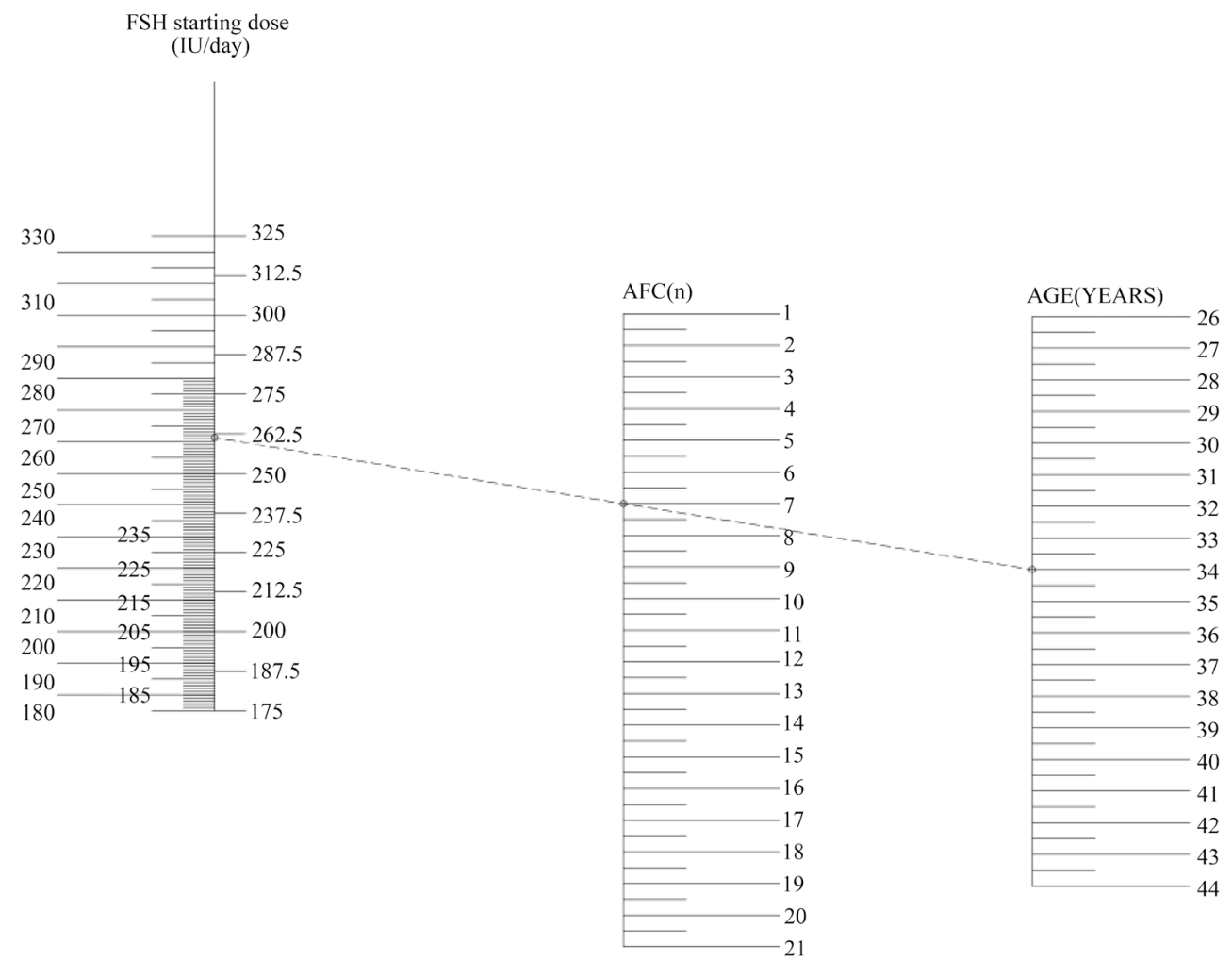

Figure 4. Nomogram of age and AFC level. 


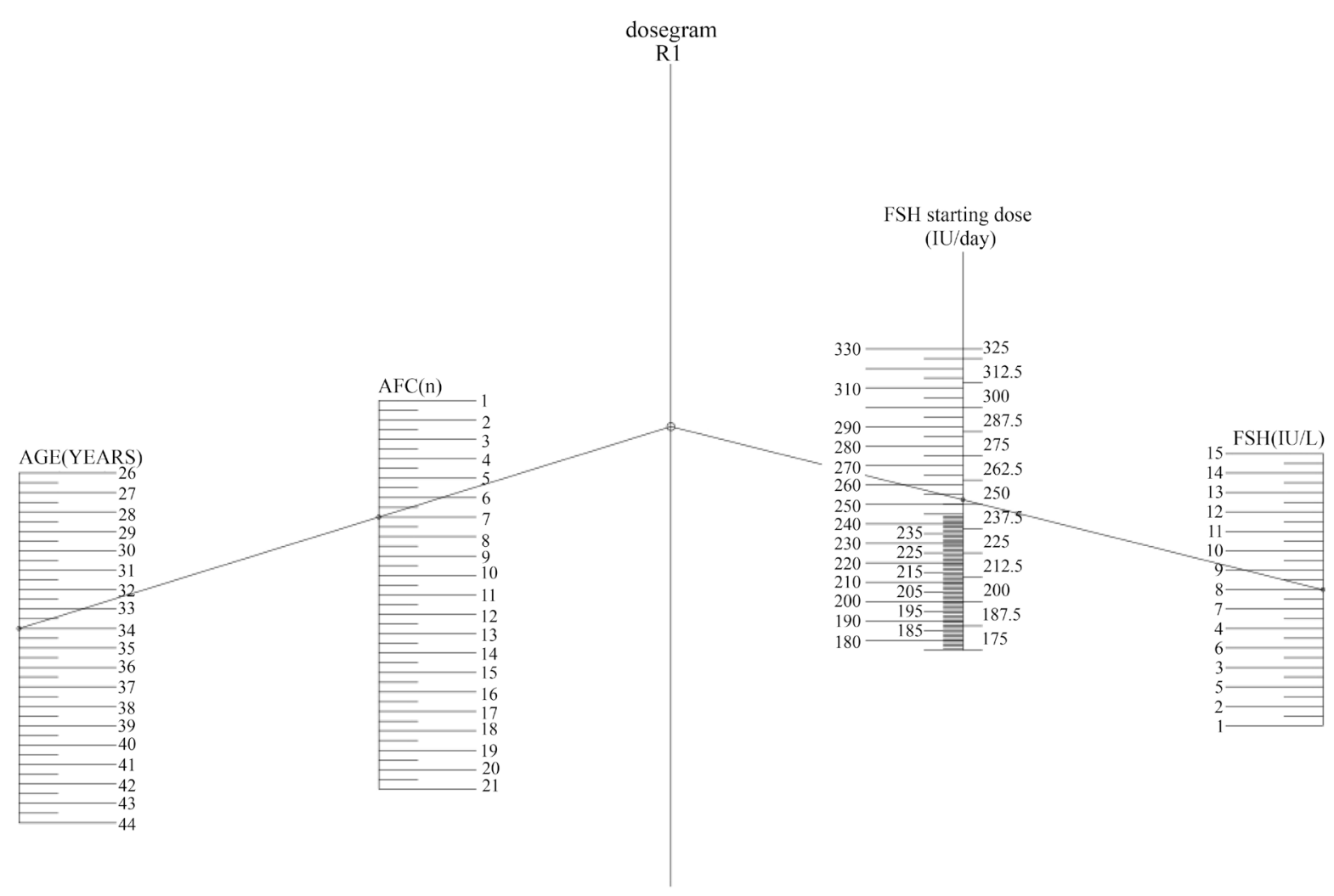

Figure 5. Nomogram of FSH level.

gram to calculate the correct FSH starting dose for IVF therapy. Its validity and accuracy still need to be confirmed.

\section{References}

[1] Fauser, B.C., Diedrich, K., Devroey, P., Evian Annual Reproduction Workshop Group (2007) Predictors of Ovarian Response: Progress towards Individualized Treatment in Ovulation Induction and Ovarian Stimulation. Human Reproduction Update, 14, 1-14. http://dx.doi.org/10.1093/humupd/dmm034

[2] Alviggi, C., Humaidan, P. and Ezcurra, D. (2012) Hormonal, Functional and Genetic Biomarkers in Controlled Ovarian Stimulation: Tools for Matching Patients and Protocols. Reproductive Biology and Endocrinology, 10, 9. http://dx.doi.org/10.1186/1477-7827-10-9

[3] Broekmans, F.J., Kwee, J., Hendriks, D.J., Mol, B.W. and Lambalk, C.B. (2006) A Systematic Review of Tests Predicting Ovarian Reserve and IVF Outcome. Human Reproduction Update, 12, 685-718. http://dx.doi.org/10.1093/humupd/dml034

[4] La Marca, A., Sighinolfi, G., Radi, D., Argento, C., Baraldi, E., Artenisio, A.C., Stabile, G. and Volpe, A. (2010) AntiMullerian hormone (AMH) as a Predictive Marker in Assisted Reproductive Technology (ART). Human Reproduction Update, 16, 113-130. http://dx.doi.org/10.1093/humupd/dmp036

[5] Nelson, S.M., Yates, R.W. and Fleming, R. (2007) Serum Anti-Müllerian Hormone and FSH: Prediction of Live Birth and Extremes of Response in Stimulated Cycles-Implications for Individualization of Therapy. Human Reproduction, 22, 2414-2421. http://dx.doi.org/10.1093/humrep/dem204

[6] Broekmans, F.J., de Ziegler, D., Howles, C.M., Gougeon, A., Trew, G. and Olivennes, F. (2010) The Antral Follicle Count: Practical Recommendations for Better Standardization. Fertility and Sterility, 94, 1044-1051. http://dx.doi.org/10.1016/i.fertnstert.2009.04.040

[7] La Marca, A., Spada, E., Sighinolfi, G., Argento, C., Tirelli, A., Giulini, S., Milani, S. and Volpe, A. (2011) AgeSpecific Nomogram for the Decline in Antral Follicle Count throughout the Reproductive Period. Fertility and Sterility, 95, 684-688. http://dx.doi.org/10.1016/j.fertnstert.2010.07.1069

[8] Broer, S.L., Dólleman, M., Opmeer, B.C., Fauser, B.C., Mol, B.W. and Broekmans, F.J. (2011) AMH and AFC as 
Predictors of Excessive Response in Controlled Ovarian Hyperstimulation: A Meta-Analysis. Human Reproduction Update, 17, 46-54. http://dx.doi.org/10.1093/humupd/dmq034

[9] Hendriks, D.J., Kwee, J., Mol, B.W., te Velde, E.R. and Broekmans, F.J. (2007) Ultrasonography as a Tool for the Prediction of Outcome in IVF Patients: A Comparative Meta-Analysis of Ovarian Volume and Antral Follicle Count. Fertility and Sterility, 87, 764-775. http://dx.doi.org/10.1016/j.fertnstert.2006.11.006

[10] Broekmans, F.J., Faddy, M.J., Scheffer, G. and te Velde, E.R. (2004) Antral Follicle Counts Are Related to Age at Natural Fertility Loss and Age at Menopause. Menopause, 11, 607-614. http://dx.doi.org/10.1097/01.GME.0000123643.76105.27

[11] Nelson, S.M., Yates, R.W., Lyall, H., Jamieson, M., Traynor, I., Gaudoin, M., Mitchell, P., Ambrose, P. and Fleming, R. (2009) Anti-Müllerian hormone-Based Approach to Controlled Ovarian Stimulation for Assisted Conception. Human Reproduction, 24, 867-875. http://dx.doi.org/10.1093/humrep/den480

[12] Yates, A.P., Rustamov, O., Roberts, S.A., Lim, H.Y., Pemberton, P.W., Smith, A. and Nardo, L.G. (2011) AntiMullerian Hormone-Tailored Stimulation Protocols Improve Outcomes whilst Reducing Adverse Effects and Costs of IVF. Human Reproduction, 26, 2353-2362. http://dx.doi.org/10.1093/humrep/der182

[13] La Marca, A., Papaleo, E., Grisendi, V., Argento, C., Giulini, S. and Volpe, A. (2012) Development of a Nomogram Based on Markers of Ovarian Reserve for the Individualization of the FSH Starting Dose in IVF Cycles. British Journal of Obstetrics and Gynaecology, 119, 1171-1179. http://dx.doi.org/10.1111/j.1471-0528.2012.03412.x 